\title{
IMPLEMENTATION OF ANALYTIC HIERARCHY PROCESS IN SOLVING TRAFFIC PROBLEMS
}

\author{
Danijela Barić \\ E-mail: danijela.baric@fpz.hr \\ Martin Starčević \\ E-mail: martin.starcevic@fpz.hr \\ Faculty of Transport And Traffic Sciences \\ University of Zagreb \\ Zagreb, CROATIA
}

\begin{abstract}
The paper presents the analysis of implementing the Analytic Hierarchy Process (AHP) in solving the problems in the area of traffic. The traffic sector is one of the most important sectors of the present times and an efficient traffic system requires continuous planning. The projects of investing into the traffic infrastructure are investment projects that are characterised by a number of specifics. These are the projects that have an extremely long lifetime (some thirty years), they are not profit-oriented, as a rule they are financed by the state of the local administration, and they are primarily of use for the social community. The decision-making process, which includes also making decisions on investments is an extremely complex one, and the decision-maker has to envisage the future, and consequently make the decisions in a modern and flexible manner.

The methods used in the process of evaluating the investment projects in traffic are numerous, and usually distinguished by the optimisation criteria. The projects, namely, cannot be evaluated through the prism of a single criterion, nor based on several criteria either. The most common optimisation criterion is of economic character; however, for the purpose of long-term and high-quality solutions it is necessary to introduce, apart from the economic criterion also other optimisation criteria such as the technological, technical, ecological and many others. Therefore, in such situations it is essential to implement the methods of multi-criteria decision-making which will eventually result in making the optimal decision. It will be determined in the paper to which extent the AHP method for decision-making regarding traffic problems is implemented and for which categories of traffic problems.
\end{abstract}

Key words: multi-criteria decision-making; Analytic Hierarchy Process; transportation 


\section{Introduction}

Traffic represents the bloodstream of every country, and thus also the basic assumption of its economic and other activities. The level of development of the traffic system is in correlation with the level of economic development and the quality of the living conditions, and thus the entire economy of a country, region or area depends on traffic. Therefore, it is in vital interest of every social community to continuously upgrade the level of quality of the traffic system. Traffic problems are not isolated and independent and their solving requires interdisciplinary approach. Planning of projects in traffic can be characterized as a process of creative optimisation of using available resources. The analyses have shown that in practice, i.e. in pre-investment and investment studies, whose aim is the financial efficiency of a project, more often the methods that rely on a single criterion are used. One of such methods is the cost-benefit analysis and it is used in the perspective of financial decision-making. The projects evaluated in this manner are acceptable if they have been positively assessed according to certain criteria of financial decision-making, i.e. expressed in monetary values. On the other hand, in scientific papers, when selecting an optimal project in the process of its analysis, acceptance or rejection, other criteria are used as well, which are not based exclusively on the criteria of financial categories, monetary flows, and their time preferences. It is, namely, because of the complexity of the traffic system, that the approach of assessing a project with several criteria is important. The implementation of several criteria is used in assessing the projects using multi-criteria decision-making methods.

One of the most frequently applied methods to assess the projects in traffic is The Analytic Hierarchy Process. It was developed by Thomas Saaty in the 1970s in order to solve the complex problems of decision-making. It is one of the best known and most verified and most used decision-making methods, i.e. method for multi-criteria analysis. Its basic advantage is reflected in the possibility of adjustment of the decision maker regarding the number of attributes, i.e. criteria and alternatives about the decision is being made simultaneously, and which can be described both quantitatively and qualitatively. Therefore, AHP method allows flexibility of the decision-making process and helps the decision makers to set the priorities, and to make the best decision taking into consideration both qualitative and quantitative aspects of decisions.

The implementation of Analytic Hierarchy Process is significant in major investment projects that require substantial capital engagement, and have high social significance (e.g. traffic infrastructure investment projects).

\section{Literature Review}

Abastante, F., Bottero,M., \& Lami, I. M., Using The Analytic Network Process For Addressing A Transport Decision Problem, International Journal of the Analytic Hierarchy Process, 4(2012), 1, 41-60

Barić, D, Čurepić, D., \& Radačić, Ž., Implementation of relevant methods in assessing traffic-technological projects, Promet - Traffic \& Transportation, 19(2007), 5, 329-336. 
Islam, R., \& Saaty, T.L. The Analytic Hierarchy Process in the Transportation Sector, Proceedings of the 19th International Conference on Multiple Criteria Decision Making, Auckland, New Zealand, 7th - 12th January 2008, 634(2008), 79-91.

\section{Objectives}

For solving traffic problems various methods are used, single- or multi-criteria ones.

The objective of the paper is to determine to which extent the AHP method is used for the decision-making in traffic problems and for which categories of traffic problems.

\section{Methodology}

By reviewing the available literature, scientific papers, technical papers, diploma theses, doctoral dissertations and projects in the area of traffic, the areas of traffic will be classified in which AHP is usually implemented, the category of papers will be determined in which AHP is usually used and the frequency of implementing AHP will be defined. Relevant bases will be analyzed.

\section{Limitations}

The analysis of the papers in which AHP method is implemented for solving the problems in the area of traffic primarily meant searching through single bases according to the key words in the title of the paper. However, numerous papers in which AHP has been implemented have no AHP in their title. Therefore, it may be expected that the research results will deviate to a certain extent from the actual situation.

\section{Conclusions}

Based on the previous research it may be concluded that the implementation of AHP in solving the problems in the area of traffic is extremely high. The analysis of relevant bases has shown that AHP method is implemented in scientific papers, scientific projects, diploma theses and doctoral dissertations.

Although only CBA is still usually implemented in practice, the number of scientific papers based on AHP method is an indicator for the justification of implementing this method in practice as well, i.e. in pre-investment and investment studies.

\section{Key References}

Abastante, F., Bottero,M., \& Lami, I. M., Using The Analytic Network Process For Addressing A Transport Decision Problem, International Journal of the Analytic Hierarchy Process, 4(2012), 1, 41-60

Barić, D, Čurepić, D., \& Radačić, Ž., Implementation of relevant methods in assessing traffic-technological projects, Promet - Traffic \& Transportation, 19(2007), 5, 329-336. 
IJAHP Article: Mu, Saaty/A Style Guide for Paper Proposals To Be Submitted to the International Symposium of the Analytic Hierarchy Process 2014, Washington D.C., U.S.A.

He, G., Some Applications of AHP to the Urban Traffic System, Proceedings of the 2nd International Symposium on The Analytic Hierarchy Process, Pittsburgh, PA, 1991, 521534.

Islam, R., \& Saaty, T.L. The Analytic Hierarchy Process in the Transportation Sector, Proceedings of the 19th International Conference on Multiple Criteria Decision Making, Auckland, New Zealand, 7th - 12th January 2008, 634(2008), 79-91.

Pogarčić, I., Frančić, M., \& Davidović, V. (2008). Application of AHP Method in Traffic Planning, Proceedings of 16th International Symposium on Electronics in Transport, Slovenia, Ljubljana, 9th - 10th October, 2008.

Rabbani, S. J., \& Rabbani, S.R. (1996). Decisions in Transportation with the Analytic Hierarchy Process, Brazil: Civil Engineering Department, Federal University of Paraiba.

Saaty, T.L. (1990). Multicriteria decision making: The Analytic Hierarchy Process. Pittsburgh: RWS Publications.

Saaty, T.L. An Essay on How Judgment and Measurement are Different in Science and in Decision Making, International Journal of the Analytic Hierarchy Process, 1(2009), 1, 6162 